Research Article

\title{
Investigation of the Hydraulic Servo System of the Rolling Mill Using Nonsingular Terminal Sliding Mode-Active Disturbance Rejection Control
}

\author{
Jining Guo $\mathbb{D}^{1,2}$ Haoyu Zhang, ${ }^{3}$ and Desheng Liu ${ }^{4}$ \\ ${ }^{1}$ Northeast Forestry University, College of Mechanical and Electrical Engineering, Harbin 150040, China \\ ${ }^{2}$ BOHAI University, Engineering College, Jinzhou 121013, China \\ ${ }^{3}$ Shenyang University of Technology, School of Material Science and Engineering, Shenyang 110870, China \\ ${ }^{4}$ Jiamusi University, School of Information and Electronic Technology, Jiamusi 154007, China
}

Correspondence should be addressed to Jining Guo; guojining1@163.com

Received 17 June 2020; Revised 13 October 2020; Accepted 23 November 2020; Published 10 December 2020

Academic Editor: En Qiang Lin

Copyright (c) 2020 Jining Guo et al. This is an open access article distributed under the Creative Commons Attribution License, which permits unrestricted use, distribution, and reproduction in any medium, provided the original work is properly cited.

In order to improve the disturbance rejection ability and tracking accuracy of the hydraulic servo system of the rolling mill, this study combines nonsingular terminal sliding mode control (NTSMC) with active disturbance rejection control (ADRC). A fourth-order extended state observer was designed to estimate the disturbance of the system in real time. The stability of the control system was tested using the Lyapunov method. System effectiveness was verified through simulation experiments. Simulation results showed that the designed state observer can estimate the total disturbance of the system in real time and that the chattering of the control input can be eliminated by the introduction of a state observer. In terms of uncertainty in the system model caused by load changes and external interference signals, the nonsingular terminal sliding mode-active disturbance rejection control method exhibited better disturbance rejection capacity and a higher tracking accuracy than NTSMC.

\section{Introduction}

The hydraulic servo system is widely used in aerospace, industrial machinery, robotics and manipulator movement, and metallurgy $[1,2]$. Hydraulic servo drive control has also become a research focus for various research institutes. The fluctuation of system pressure, changes in friction force and oil compressibility, viscosity, and pressure and temperature will cause internal disturbances of the system. Changes in load condition are the main cause of the external disturbance. Consequently, the system model is nonlinear and uncertain [3-6]. Classical PID control methods describe the dynamics of the hydraulic servo system as a set of linear equations that define the design of the corresponding controller. In practical industrial applications, it is difficult to obtain satisfactory dynamic and static characteristics.

High-speed convergence is an important requirement of the hydraulic servo control system, and most existing control laws are asymptotically stable. Of these laws, the finite-time control law has clear advantages. Under optimal control conditions, a variety of finite-time control laws have been developed for first-order and second-order control systems $[7,8]$. In low-order systems, the continuous finitetime state feedback control is frequently adopted, which usually requires a certain system model and has no obvious effect on the disturbance input of the system [9-11]. For finite-time control of higher-order systems, the backstepping control is mainly adopted; however, due to the existence of powers less than 1 , singular phenomena can still occur [12]. Terminal sliding mode (TSM) control is an effective finite-time control scheme [13, 14], different from the traditional sliding mode control in that a nonlinear sliding mode manifold is introduced. Nonetheless, there are still two drawbacks: the first is the singular value problem, and the second occurs when the system state is far from equilibrium and its convergence speed is slow. To address the first 
problem, a nonsingular terminal sliding mode control (NTSMC) [15] has been proposed. For the second problem, a fast terminal sliding mode control (FTSMC) has been developed [16]. In addition, when solving the synthesis problem of very complex nonlinear systems, parameter perturbation and the invariance of external disturbances will cause high-frequency chatting of the control quantity. For practical applications, this kind of high-frequency chatting cannot be realized by any actuator. Methods to reduce chatting include adjusting the approach law, introducing a filter and interference observer, and the dynamic sliding mode [17-19]. At present, the terminal sliding mode control has been applied in the hydraulic position servo system. Shen et al. [20] combined state feedback with the backstepping sliding mode control to enable finite-time control of the second-order hydraulic servo system; however, when the disturbance exceeds a certain range, the state observer will show significant deviations, and the accuracy of control will be affected.

On the contrary, improving the antidisturbance performance of the system is expected by all control methods. Active disturbance rejection control (ADRC) is an effective method through which the disturbance rejection capability of uncertain systems can be improved. This method was proposed by Professor Han Jingqing on the basis of nonlinear PID control [21], which has the characteristics of not relying on an accurate model of the system, strong antidisturbance ability, a simple algorithm, and ease of implementation [22]. It is thus widely used in mechanical and electrical systems, aerospace and chemical engineering, and other fields [23-27]. Research on its theory is extensive [28-30]. ADRC consists of three parts, namely, the tracker differentiator (TD), the extended state observer (ESO), and the nonlinear state error feedback (NLSEF). The basis of this idea is to use the state observer to estimate internal parameter uncertainty and the external nondisturbance of the system in real time. By using nonlinear state error feedback to compensate, the antidisturbance capability of the system is improved on the premise that only an input and output are required of the system. Aiming to address the uncertainty of hydraulic servo control systems, Yao and Deng [31] designed an ADRC system and proved that it was asymptotically stable. Wang et al. [32] applied ADRC to the reduced-order model of the hydraulic servo system and proved the effectiveness of the method through an experimental approach. However, for sudden disturbances, systems are still prone to overshoot and chatting. Gao et al. [33] proposed an active disturbance rejection control scheme with velocity compensation, which used the extended state observer to observe system disturbance and improve anti-interference abilities, but did not analyze system stability. It is thought that terminal sliding mode control and ADRC are very effective control methods for uncertain systems. Nonetheless, in previous research, the second-order system model is the main research object. To solve the problem of terminal sliding mode control being unsuitable for buffering of highorder systems and control signals, a composite control strategy combining a nonsingular terminal sliding mode with ADRC is proposed herein. The main idea of this approach was to combine the advantage of finite-time convergence in the nonsingular terminal sliding mode control method with the ability of the ADRC to suppress external interference and model uncertainty and achieve smooth tracking of the hydraulic position servo system. Firstly, TD was used to obtain the differential signal of the input trajectory, and ESO was used to obtain estimated values of displacement, angular velocity, acceleration, and total disturbance of the hydraulic servo system. Nonlinear terminal sliding mode control law was used as the error feedback control law to compensate the total disturbance of the system, and a sliding mode controller was designed based on ADRC. Secondly, the stability of the system was proved using the Lyapunov method. Finally, system effectiveness was verified using the simulation experiments.

This paper is organized as follows. The second section introduces the mathematical model of the hydraulic servo system of the rolling mill. The third section proposes the design of an ADRC based on nonsingular sliding mode control, and the stability of the system is proved using the Lyapunov method. In the fourth section, the hydraulic servo system is simulated under different working conditions. Section five presents our conclusions.

\section{Mathematical Model of the Hydraulic Servo System of the Rolling Mill}

A schematic of the hydraulic servo system of the rolling mill is shown in Figure 1, which is composed of a servo amplifier, servo valve, hydraulic cylinder, and position transducer. The mass spring system is an external load, and the servo valve drives the movement of the hydraulic cylinder, which itself is controlled to keep the displacement of the hydraulic cylinder as close as possible to the desired trajectory, regardless of the operating point.

The mathematical model consists of three main equations, i.e., the servo valve flow equation, the cylinder flow continuous equation, and the piston force balance equation [17]. The servo valve flow equation is a typical nonlinear equation, which can be given as follows [34]:

$$
Q_{l}=c_{d} \omega x_{r} \sqrt{\frac{p_{s}-p_{l} \cdot \operatorname{sgn}\left(x_{r}\right)}{\rho}} \partial,
$$

where $Q_{l}$ is the load flow, $c_{d}$ is the valve port flow coefficient, $\omega$ is the servo valve opening gradient, $x_{r}$ is the servo core displacement, $P_{s}$ is the hydraulic pump outlet pressure, $P_{1}$ is the load pressure, and $\rho$ is the hydraulic oil density. Considering leakage and compressibility of the oil, the flow continuity equation of the oil cylinder can be written as follows [34]:

$$
Q_{l}=A_{p} \dot{x}+c_{t} p_{l}+\frac{V}{4 \beta_{e}} \dot{p}_{l}
$$

where $A_{p}$ is the hydraulic cylinder piston effective area, $x$ is the cylinder piston displacement, $c_{t}$ is the hydraulic cylinder leakage coefficient, $V$ is the total volume of the hydraulic cylinder body, and $\beta_{e}$ is the bulk modulus of elasticity. Ignoring the servo valve dynamic, the servo amplifier and 


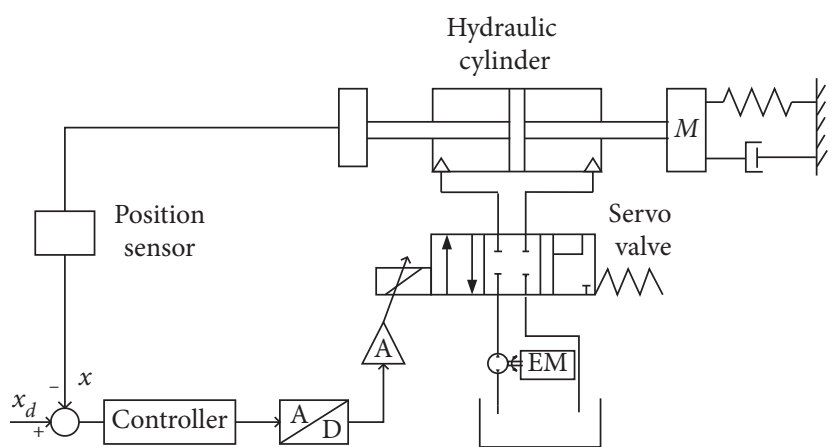

FIgURE 1: Schematic diagram of the hydraulic position servo system.

servo valve equivalent proportional link can be written as follows:

$$
\begin{gathered}
k_{p}=\frac{i}{u}, \\
k_{\mathrm{sr}}=\frac{x_{r}}{i},
\end{gathered}
$$

where $k_{\mathrm{sr}}$ is the servo valve gain and $i$ is the output current of the servo amplifier. [34]

The piston force balance equation can be given as follows

$$
A_{p} p_{l}=m \ddot{x}+B_{p} \dot{x}+k x+F_{l},
$$

where $m$ is the total mass of the piston and the load, $B_{p}$ is the viscous damping coefficient of the piston, $k$ is the elastic stiffness coefficient of the piston, and $F_{l}$ is the accidental load on the piston.

Let $x_{1}=x, x_{2}=\dot{x}$, and $x_{3}=\ddot{x}$, and the state-space expression is as follows:

$$
\left\{\begin{array}{l}
\dot{x}_{1}=x_{2}, \\
\dot{x}_{2}=x_{3}, \\
\dot{x}_{3}=a_{1} x_{1}+a_{2} x_{2}+a_{3}+a_{4} g\left(x_{r}\right) u+d, \\
y=x_{1},
\end{array}\right.
$$

where $u$ is the control input of the system, $y$ is the output of the system, and $d$ is the disturbance caused by load change.

\section{Controller Design}

For further study, model (5) may be rewritten as a thirdorder uncertain system as follows:

$$
\{\stackrel{\dot{\mathrm{t}}}{x}(t)=f(x, \dot{x}, \ddot{x}, \omega(t))+b(t) u(t)+d(t), y=x(t),
$$

where $f(x, \dot{x}, \ddot{x}, \omega(t))$ comprises the internal perturbation parameters of the system, $d(t)$ is the external disturbance of the system, and $f(x)$ and $d(t)$ are zero and correspond to two smooth nonlinear functions, assuming that $d(t)$ is bounded. The third-order active disturbance rejection control structure is shown in Figure 2.

3.1. Tracking Differentiator. The role of the TD is to arrange the transition process. The differential signal of the position of the rolling mill instruction signal is given by the TD. The tracking signal $x_{1}$, the first-order differential signal $x_{2}$, and the second-order differential signal $x_{3}$ of the reference instruction signal are generated and can effectively alleviate overshoot phenomena caused by the excessive initial error and the contradiction between the rapid response and overshoot of the system. The designed discrete tracking differential algorithm of the third-order TD is thus 


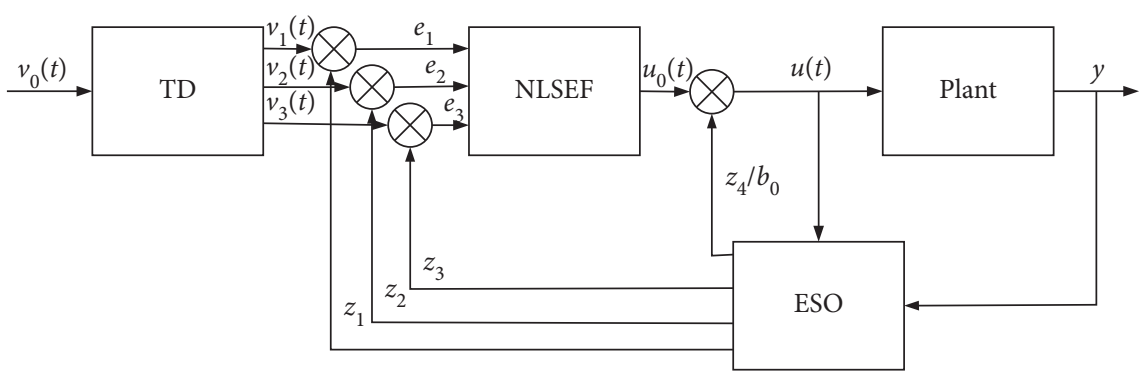

FIGURE 2: Control system block diagram of active disturbance rejection control (ADRC).

$$
\left\{\begin{array}{l}
u=\text { fhan }\left(x_{1}(k), v(k), x_{2}(k), r, h\right), \\
x_{1}(k+1)=x_{1}(k)+T x_{2}(k), \\
x_{2}(k+1)=x_{2}(k)+T x_{3}(k), \\
x_{3}(k+1)=x_{3}(k)+T u,
\end{array}\right.
$$

$$
\left\{\begin{array}{l}
d=r h, \\
d_{0}=h d, \\
y=x_{1}-v+h x_{2}, \\
a_{0}=\sqrt{d^{2}+8 r|y|}, \\
a=\left\{\begin{array}{l}
x_{2}+\frac{\left(a_{0}-d\right)}{2} \operatorname{sign}(y), \quad|y|>d_{0}, \\
x_{2}+\frac{y}{h}, \quad|y| \leq d_{0},
\end{array} \quad \text { fhan }=\left\{\begin{array}{l}
r \operatorname{sing}(a), \quad|a|>d, \\
-r \frac{a}{d}, \quad|a| \leq d .
\end{array}\right.\right.
\end{array}\right.
$$

The tracking differentiator enables the smooth approximation of the input signal and the extraction of the differential signal and has some filtering effects on the random noise signal. The parameters to be set are $r, h$, and $h_{0}$, which are mainly determined by the empirical method. Generally, one will choose $r=\left(0.0001 / h^{2}\right)$. As a filter factor, the larger the value of $h_{0}$, the better the filtering effect. However, an excessive value will cause lag in tracking, and the two effects will be contradictory. We thus choose $h_{0}=20 h$.

For the third-order uncertain system described by equation (6), the TD designed by formulae (7) and (8) is ultimately convergent $[35,36]$ and can enable the transition of the input signal and tracking output of the TD to a sinusoidal signal. As shown in Figure 3, there is vibration near the origin when second-order tracking signals are calculated. where $T$ is the sampling period, $v(k)$ is the input signal at moment $k, x_{1}(k)$ is the tracking filter signal of $v(k), x_{2}(k)$ is the first derivative of $v(k), x_{3}(k)$ is the second derivative of $v(k), r$ is the speed factor, $h$ is the filter factor of the instruction signal, and fhan $\left(x_{1}, x_{2}, v, r, h\right)$ is the designed synthesis function of fast optimal control, and its specific algorithm is as follows:
3.2. Extended State Observer. For the uncertain system shown in equation (1), we select state variables $x, \dot{x}, \ddot{x}$, and $\stackrel{t}{x}$ for observation, and the nonlinear state observer is thus constructed as follows [37]:

$$
\left\{\begin{array}{l}
\varepsilon_{1}=z_{1}-y \\
\dot{z}_{1}=z_{2}-\beta_{01} \varepsilon_{1}, \\
\dot{z}_{2}=z_{3}-\beta_{02} \text { fal }\left(\varepsilon_{1}, \alpha_{1}, \delta\right), \\
\dot{z}_{3}=z_{4}-\beta_{03} \text { fal }\left(\varepsilon_{1}, \alpha_{2}, \delta\right)+b_{0} u, \\
\dot{z}_{4}=-\beta_{04} \text { fal }\left(\varepsilon_{1}, \alpha_{2}, \delta\right),
\end{array}\right.
$$

where $z_{1}, z_{2}$, and $z_{3}$ are the observations of $x_{1}, x_{2}$, and $x_{3}$ and $z_{4}$ is the observation of the total disturbance of the system. For system (6), the above approach is followed: a nonlinear function fal is selected to design a fourth-order 


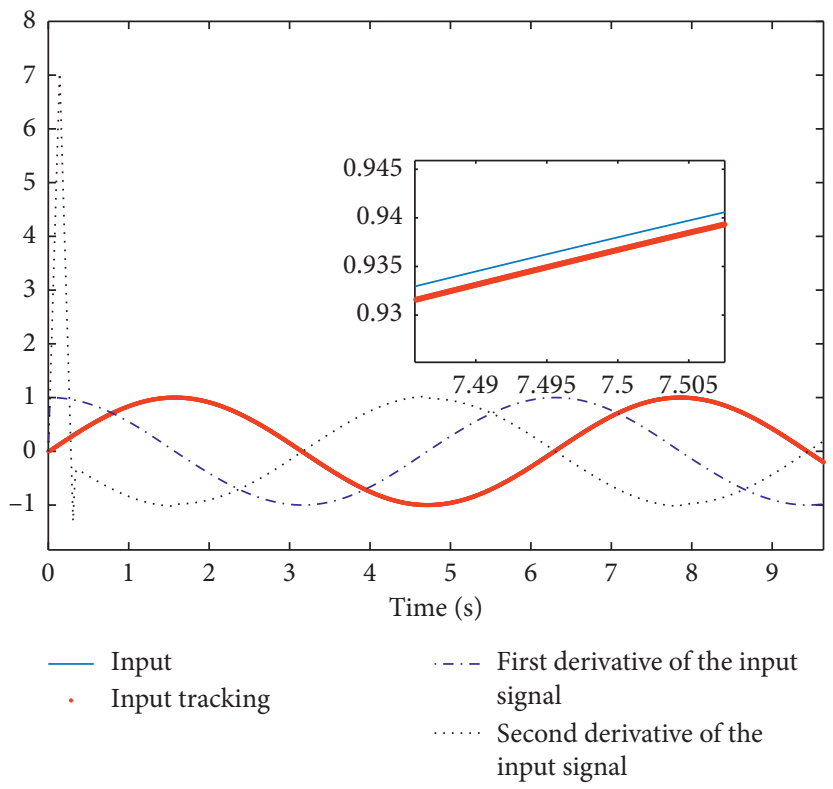

FIgURE 3: Tracking output of the tracker differentiator (TD).

ESO for real-time fast estimation of the system state variables and its total disturbance.

$$
\operatorname{fal}\left(e_{i}, \alpha_{i}, \delta\right)= \begin{cases}\left|e_{i}\right|^{\alpha_{i}} \operatorname{sign}\left(e_{i}\right), & \left|e_{i}\right|>\delta, \\ \frac{e_{i}}{\delta^{1-\alpha_{i}}}, & \left|e_{i}\right| \leq \delta, \delta>0 .\end{cases}
$$

The parameters that the nonlinear function needs to determine are $\alpha_{1}, \alpha_{2}, \alpha_{3}$, and $\delta$. $\alpha_{i}$ determines the shape of the nonlinear function, and $\delta$ determines the magnitude of the linear interval. Generally, one takes $\delta_{0}=0.02$, $\alpha_{1}=0.5, \alpha_{2}=0.25$, and $\alpha_{3}=0.125 . \beta_{01}, \beta_{02}, \beta_{03}, \beta_{04}$, and $b_{0}$ are the parameters to be set. According to the bandwidth principle, this should be written as $s^{4}+\beta_{01} s^{3}+\beta_{02} s^{2}+\beta_{03} s+\beta_{04}=\left(s+\omega_{0}\right)^{4}$, where $\omega_{0}$ is the bandwidth of the observer and $b_{0}$ is the estimate of parameter $b$, which has a physical meaning that is more important. It not only determines the control law $u$ but also affects the interval variation of the total disturbance. The selection of its value cannot be accomplished immediately; instead, it needs to be adjusted repeatedly according to the experience after the selection of the other parameters; finally, an ideal result can be obtained.

For the third-order uncertain system described by formula (6), the ESO designed by formula (9) is adopted. In the case of uncertainty in the object model, the state estimation effect of the system is shown in Figure 4. It can be seen that the outputs of the observed values of $z_{1}$ and $z_{2}$ have a high estimation accuracy such that $z_{3}$ and $z_{4}$ can also estimate the state output with a slightly lower accuracy.

3.3. Nonsingular Terminal Sliding Mode Control. In order to improve the tracking accuracy and speed, the nonsingular fast terminal sliding mode control method is introduced into the nonlinear feedback control law. On the basis of [38], a design method of nonsingular fast terminal sliding mode control is presented.

Firstly, we define the sliding mode manifold, i.e., let $x_{d}$ be the desired position, and this has first and second derivatives. The tracking error of the system is defined as $e_{1}=x_{1}-x_{d}, e_{2}=x_{2}-\dot{x}_{d}$, and $e_{3}=x_{3}-\ddot{x}_{d}$. The sliding mode manifold is further defined as

$$
s=e_{3}+c_{2} e_{2}^{\alpha_{2}}+c_{1} e_{1}^{\alpha_{1}}
$$

where $\alpha_{1}$ and $\alpha_{2}$ are determined by $p$ and $q$, positive odd numbers. Moreover, $((1<p) /(q<2)), \alpha_{1}=(q /(2 p-q))$, and $\alpha_{2}=(q / p) . c_{1}$ and $c_{2}$ are both constants greater than zero, the selection of which should guarantee that the polynomial $p^{2}+c_{2} p+c_{1}$ meets the Hurwitz stability criterion. The convergence of system (16) in finite time is guaranteed for the above sliding mode manifold.

For electrohydraulic servo system (2), if one selects nonsingular sliding mode manifold (10) and designs NTSMC as follows, tracking errors will converge to zero in finite time:

$$
u=-b^{-1}\left(-c_{2} \alpha_{2} e_{2}^{\alpha_{2}-1} \cdot e_{3}-c_{1} \alpha_{1} e_{1}^{\alpha_{1}-1} e_{2}+\stackrel{\dot{t}}{x_{d}}-z_{4}+M \operatorname{sgn}(s)\right),
$$

where $M$ is the controller gain.

$$
V=\frac{1}{2} s^{2}
$$

The differential of the sliding mode manifold is as follows: 

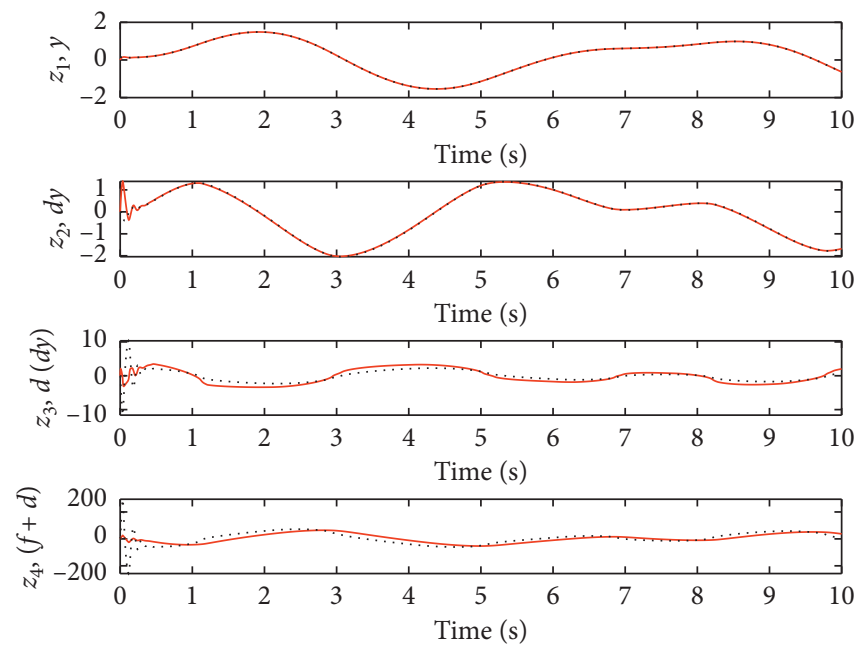

FIgURE 4: The output of the extended state observer (ESO).

$$
\begin{aligned}
& \dot{s}=\dot{e}_{3}+c_{2} \alpha_{2} e_{2}^{\alpha_{2}-1} \dot{e}_{2}+c_{1} \alpha_{1} e_{1}^{\alpha_{1}-1} \dot{e}_{1}=\dot{x}_{3}-\stackrel{\dot{t}}{x}_{d}+c_{2} \alpha_{2} e_{2}^{\alpha_{2}-1} e_{3}+c_{1} \alpha_{1} e_{1}^{\alpha_{1}-1} e_{2}, \\
& \dot{V}=s\left(\dot{x}_{3}-\stackrel{\mathrm{t}}{x}_{d}+c_{2} \alpha_{2} e_{2}^{\alpha_{2}-1} e_{3}+c_{1} \alpha_{1} e_{1}^{\alpha_{1}-1} e_{2}\right), \\
& \dot{V}=s\left(f(x)+b(x) u+d(x)-\dot{\mathfrak{t}}_{d}+c_{2} \alpha_{2} e_{2}^{\alpha_{2}-1} e_{3}+c_{1} \alpha_{1} e_{1}^{\alpha_{1}-1} e_{2}\right) .
\end{aligned}
$$

By substituting (13) into (15), one obtains

$$
\begin{aligned}
\dot{V} & =s\left(f(x)+b(x)\left(-b^{-1}\left(-c_{2} x_{2} e_{2}^{\alpha_{2}-1} \cdot e_{3}-c_{1} e_{1}^{\alpha_{1}-1} e_{2}-z_{4}+M \operatorname{sgn}(s)\right)\right)+d(x)-\stackrel{\grave{t}}{x}_{d}+c_{2} \alpha_{2} e_{2}^{\alpha_{2}-1} \cdot e_{3}+c_{1} \alpha_{1} e_{2}^{\alpha_{1}-1} \cdot e_{2}\right) \\
& =s\left(f(x)+d(x)-z_{4}+M \operatorname{sgn}(s)\right) .
\end{aligned}
$$

From (15), one can obtain a relationship in which $M>f+d-z_{4}$ and $\dot{V}<0$. It is known that the control system is stable and that its error can reach the sliding mode manifold and converge to zero in finite time.

\section{Simulation Analysis}

For electrohydraulic control system (6), Simulink was used to establish the control system model. Figure 5 shows the simulation model of the system, and Table $1[17,34]$ shows the parameters of the system.

4.1. Simulation Analysis of the No-Load Condition. Figure 6 shows the no-load situation under conditions of $k=0$ and $F 1=0$. The expectation of the system input sine signal is $x \_d=\sin (t)$. The system disturbance is $d(t)=50$ $\sin (t)$. Comparing the control performance of NTSMCADRC with that of NTSMC, Figure 6(a) shows that both controls can track the expected signal, and there is a substantial error in NTSMC within the first few seconds. It can be seen from Figure 6(b) that the designed extended state observer can observe the system disturbance in real time. As shown in Figure 6(c), the NTSMC-ADRC control signal (T) changes smoothly with the periodic line of the interference signal, for which there is no single value. Buffering is eliminated due to the estimation and compensation of the ESO for uncertain parts of the system, while jitter exists in the NTSMC signal.

Figure 7 compares the position tracking errors of the two control methods, and it can be clearly seen that the control performance of NTSMC-ADRC is better than that of NTSMC. The maximum position tracking error of NTSMCADRC is less than 0.03 , whereas the maximum position tracking error of NTSMC is around 0.1.

Figure 8 shows a comparison between the system input unit step signal and the performance of the two kinds of control considered herein. As shown in Figure 8(a), the 


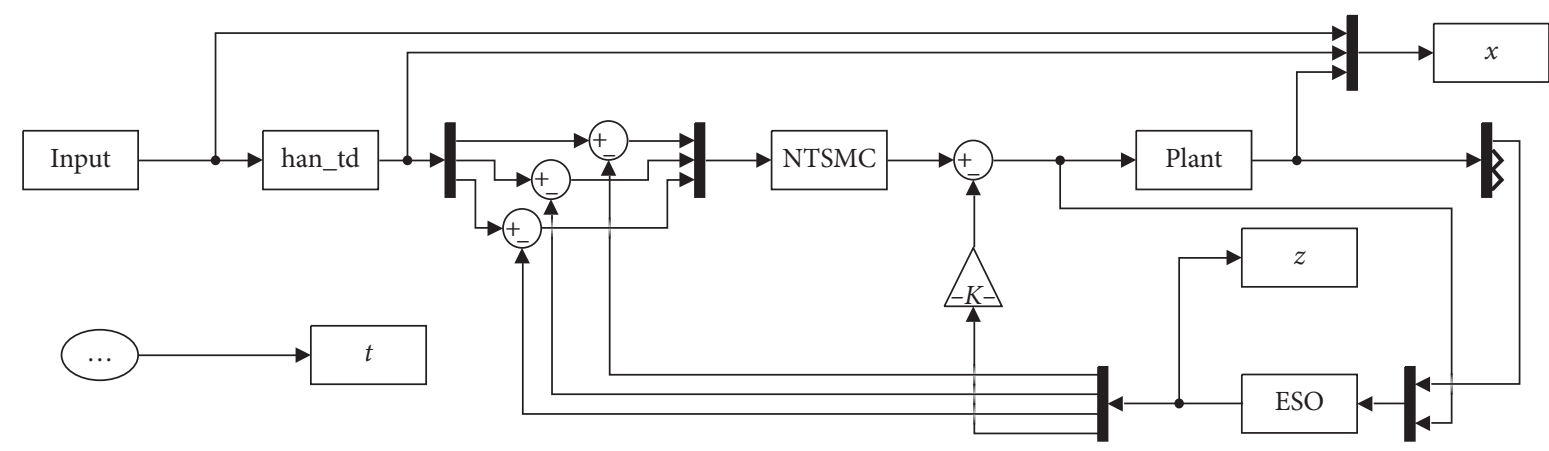

Figure 5: Simulation model of the control system.

TABLE 1: Simulation model of the control system.

Viscous damping coefficient of piston $\mathrm{Bp}(\mathrm{N} \cdot \mathrm{s} / \mathrm{m})$

\begin{tabular}{c}
$2.25 \times 10^{6}$ \\
0.01 \\
$7 \times 10^{8}$ \\
0 \\
$3.8 \times 10^{7}$ \\
850 \\
0.1256 \\
$5 \times 10^{-16}$ \\
1500 \\
$2.5 \times 10^{9}$ \\
0.61 \\
0.025 \\
$3.768 \times 10^{-3}$ \\
\hline
\end{tabular}

Servo gain coefficient $\mathrm{ksv}\left(\mathrm{m}^{3} /(\mathrm{V} \cdot \mathrm{s})\right)$

Bulk modulus of elasticity $\beta \mathrm{e}(\mathrm{Pa})$

Return pressure pr $(\mathrm{Pa})$

Hydraulic pump outlet pressure $\mathrm{Ps}(\mathrm{Pa})$

Hydraulic oil density $\rho\left(\mathrm{kg} / \mathrm{m}^{3}\right)$

Effective area of the cylinder Ap $\left(\mathrm{m}^{2}\right)$

Hydraulic cylinder leakage coefficient Ct $\left(\mathrm{m}^{5} /(\mathrm{N} \cdot \mathrm{s})\right)$

Total mass of the piston and load $m(\mathrm{~kg})$

Elastic stiffness coefficient $k(\mathrm{~N} / \mathrm{m})$

Valve flow coefficient $C_{d}$

Servo valve area gradient $w(\mathrm{~m})$

Initial volume of the hydraulic cylinder $V\left(\mathrm{~m}^{3}\right)$

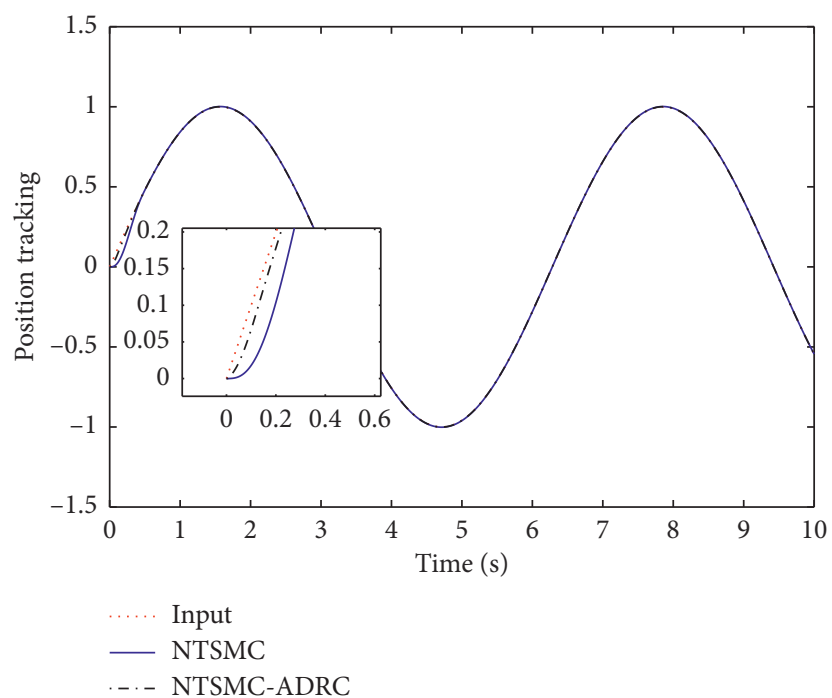

(a)

FIGURE 6: Continued. 


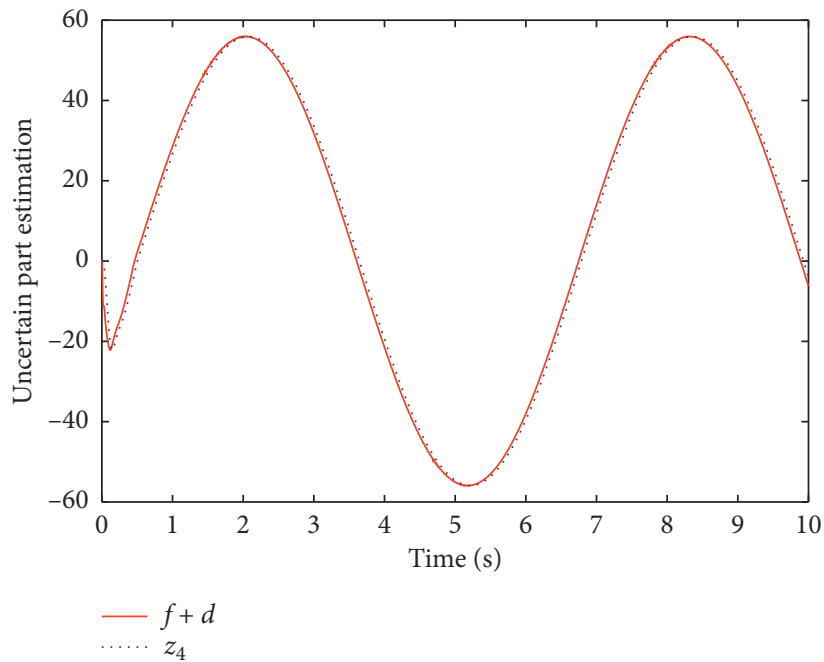

(b)

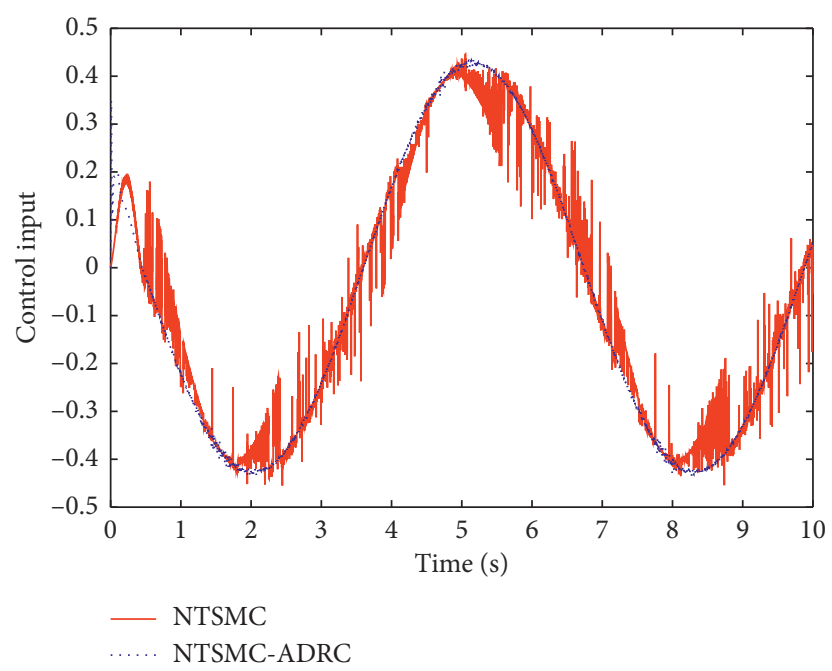

(c)

FIgURE 6: Control performance comparison between NTSMC-ADRC and NTSMC when the input is a sinusoidal signal. (a) Position tracking. (b) Interference signal estimation. (c) Control signal.

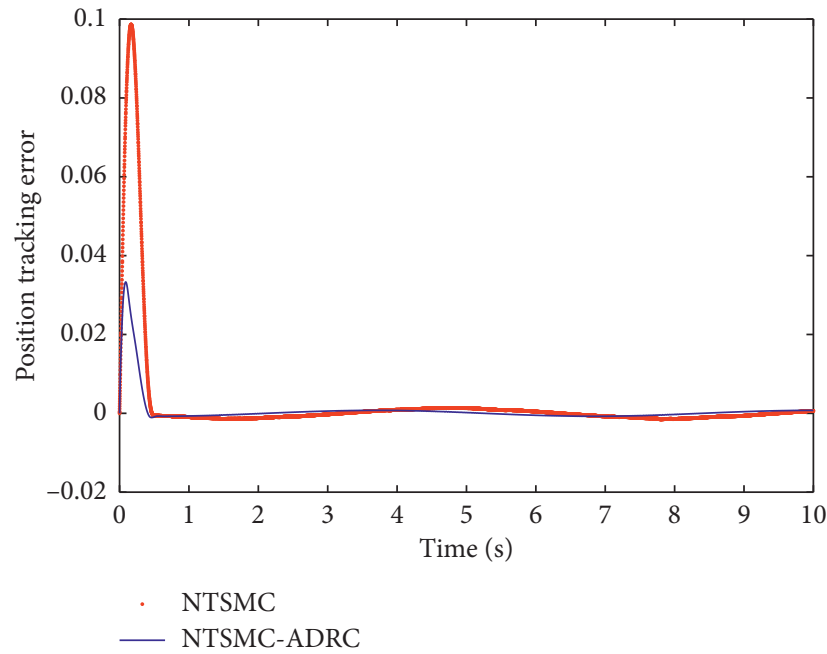

FIGURE 7: Tracking error comparison between nonsingular terminal sliding mode control-active disturbance rejection control (NTSMCADRC) and NTSMC when the input is a sinusoidal signal. 


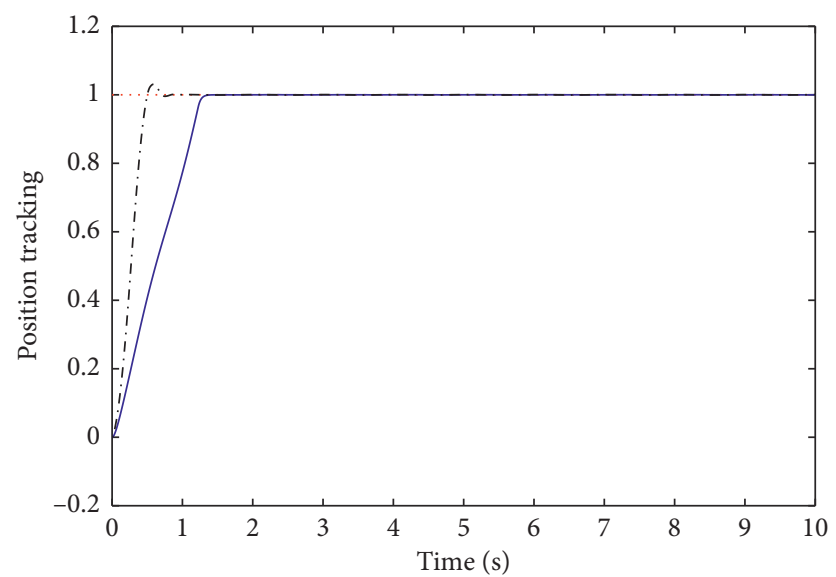

(a)

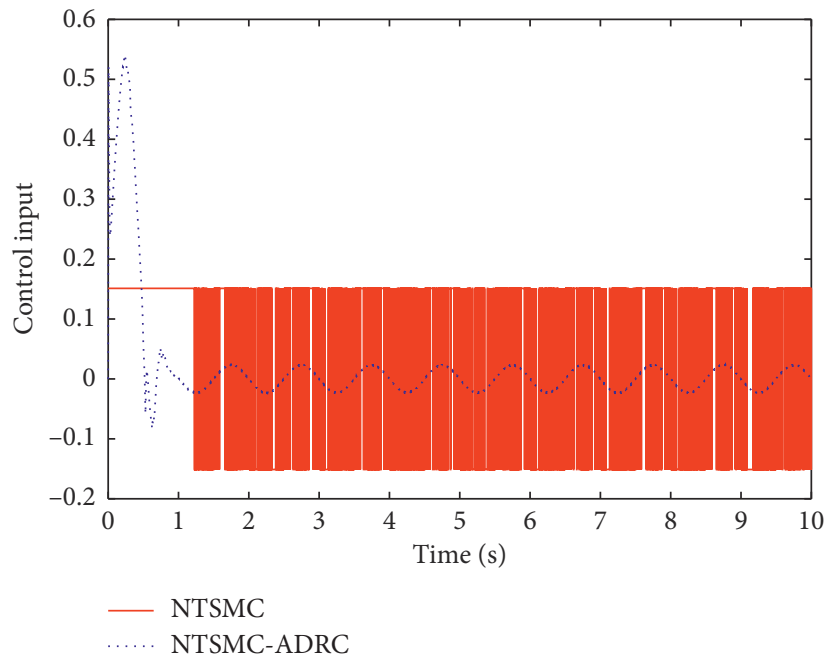

(b)

FIGURE 8: Performance comparison between nonsingular terminal sliding mode control-active disturbance rejection control (NTSMCADRC) and NTSMC when the input is a step-over signal. (a) Position tracking output. (b) Control input.

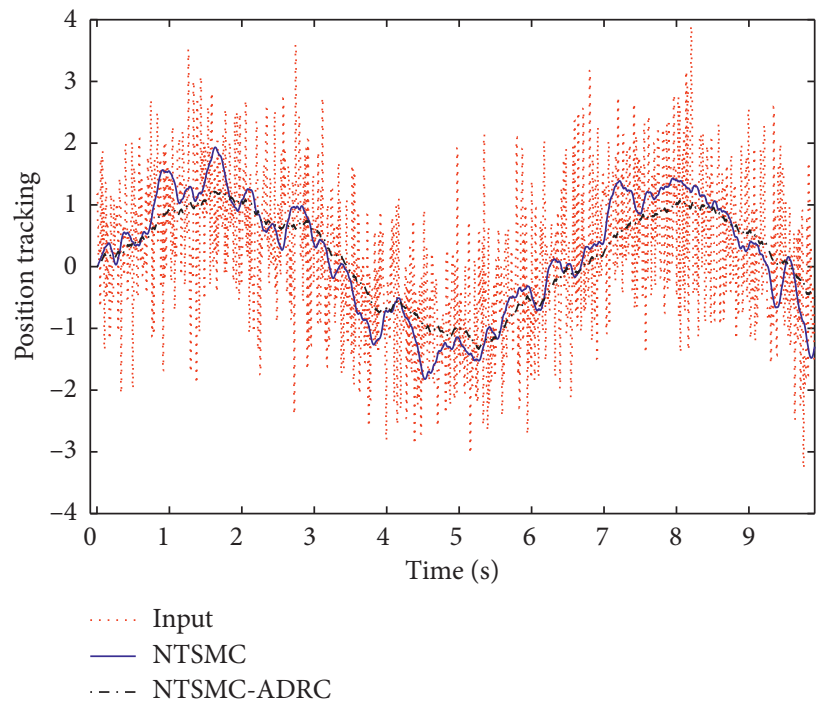

(a)

Figure 9: Continued. 


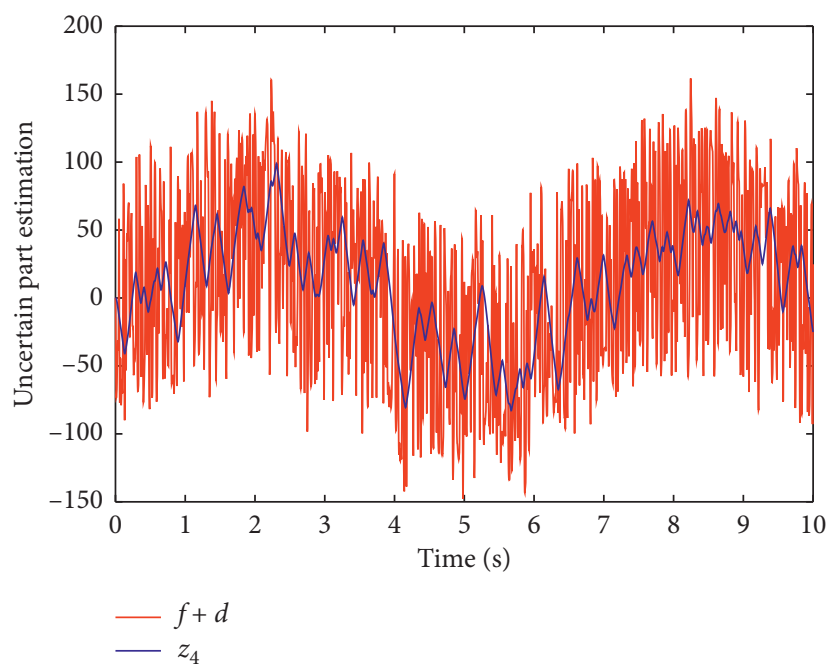

(b)

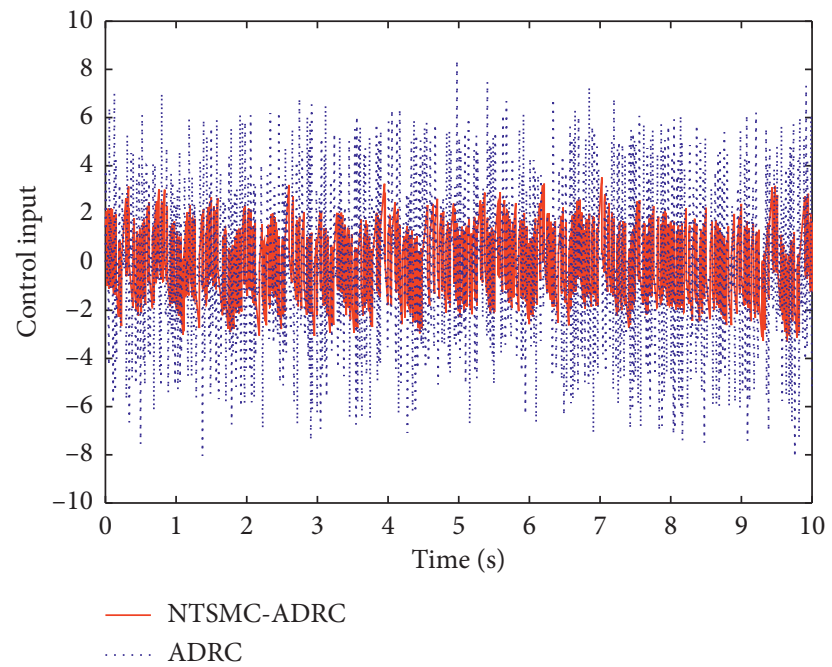

(c)

FIGURE 9: Comparison of performance between nonsingular terminal sliding mode control-active disturbance rejection control (NTSMCADRC) and NTSMC when random noise is added. (a) Position tracking. (b) Partial uncertainty estimation. (c) Control input.

NTSMC-ADRC control can track the position signal quickly and accurately. However, NTSMC has a large tracking error near zero and a slow stabilization time. Figure 8(b) shows the system control signal input and demonstrates that the NTSMC-ADRC control input exhibits a smoother curve of periodic change after 2 seconds, whereas the NTSMC input switches back and forth within a certain range.

4.2. Load Condition Simulation Analysis. According to real situations, when the roll gap is close to zero, the upper and lower rollers contact each other, and parameter jumps can occur. The piston elastic stiffness is $k=2.5 \times 10^{9}(\mathrm{~N} / \mathrm{m})$, and the external load is $F_{L}=2 \times 10^{6} \mathrm{~N}$. All other parameters are the same, and the expected value of the input is still the sinusoidal signal, which is $x_{d}=\sin (t)$. The system disturbance is $d(t)=50 \sin (2 \pi t)$. The state of the initial value is $\left[x_{10}, x_{20}, x_{30}\right]=[0,0,0]^{T}$. On this basis, simulating measurement noise or random noise signal interference requires addition to the input signal. As presented in Figure 9(a), the position output of the NTSMC-ADRC control is closer to the expected value. Figure 9(b) shows the estimation of interference signals by the state observer. Figure 9(c) shows the control input. It can be seen from Figure 9 that, in the case of external random interference, the amplitude of the NTSMC input fluctuates greatly, whereas that of NTSM-ADRC, due to the filtering effect of the TD and the estimation and compensation of the ESO in the total interference of the system, is smaller and shows only periodic change.

Figure 10 shows the comparison of tracking errors between the two control methods when the load is not zero. NTSMC-ADRC therefore has better performance than NTSMC. 


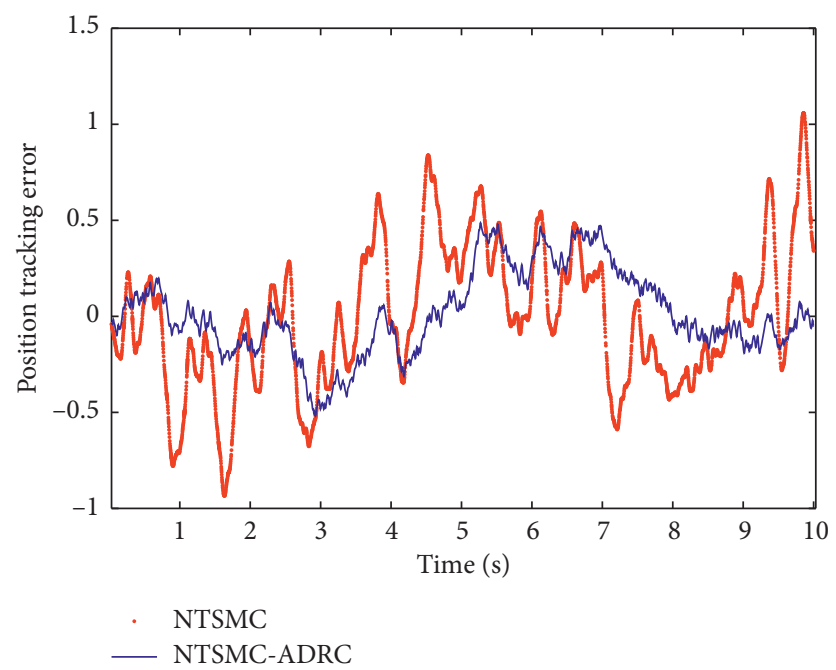

FIGURE 10: Tracking error comparison between nonsingular terminal sliding mode control-active disturbance rejection control (NTSMCADRC) and NTSMC when the input is a noise signal.

\section{Conclusions}

Aiming at addressing the uncertainty of hydraulic servo systems, this research has studied interference suppression problems. The NTSMC-ADRC controller has been designed to improve the convergence speed and anti-interference ability. The designed third-order TD can track the input signal accurately and filter random interference signals. The designed ESO can estimate the uncertain part of the model and the external interference in real time and can effectively weaken chattering caused by sliding mode control gain. The stability of the system is demonstrated using the Lyapunov method. Finally, NTSMC-ADRC and NTSMC were simulated under no-load and on-load conditions. The results of these simulations show that this method has faster adjustment time and a stronger anti-interference ability.

\section{Data Availability}

The data used to support the findings of this study are included within the article. The data in this paper (Table 1) are from Shi et al. [17].

\section{Conflicts of Interest}

The authors declare that they have no conflicts of interest.

\section{References}

[1] M. Battley and T. Allen, "Servo-hydraulic system for controlled velocity water impact of marine sandwich panels," Experimental Mechanics, vol. 52, no. 1, pp. 95-106, 2012.

[2] M.-H. Chiang, "A novel pitch control system for a wind turbine driven by a variable-speed pump-controlled hydraulic servo system," Mechatronics, vol. 21, no. 4, pp. 753-761, 2011.

[3] J. Zhao, C. French, C. Shield, and T. Posbergh, "Considerations for the development of real-time dynamic testing using servo-hydraulic actuation," Earthquake Engineering \& Structural Dynamics, vol. 32, no. 11, pp. 1773-1794, 2003.
[4] P. Wos and R. Dindorf, "Adaptive control of the electrohydraulic servo-system with external disturbances," Asian Journal of Control, vol. 15, no. 4, pp. 1065-1080, 2013.

[5] H.-Y. Zhang, J. Sun, D.-H. Zhang, S.-Z. Chen, and X. Zhang, "Improved Smith prediction monitoring AGC system based on feedback-assisted iterative learning control," Journal of Central South University, vol. 21, no. 9, pp. 3492-3497, 2014.

[6] H.-B. Yuan, H.-C. Na, and Y.-B. Kim, "System identification and robust position control for electro-hydraulic servo system using hybrid model predictive control," Journal of Vibration and Control, vol. 24, no. 18, pp. 4145-4159, 2018.

[7] W. M. Haddad and A. L'Afflitto, "Finite-time stabilization and optimal feedback control," IEEE Transactions on Automatic Control, vol. 61, no. 4, pp. 1069-1074, 2016.

[8] X. Liu, D. W. C. Ho, W. Yu, and J. Cao, "A new switching design to finite-time stabilization of nonlinear systems with applications to neural networks," Neural Networks, vol. 57, pp. 94-102, 2014.

[9] S. P. Bhat and D. S. Bernstein, "Finite-time stability of continuous autonomous systems," SIAM Journal on Control and Optimization, vol. 38, no. 3, pp. 751-766, 2000.

[10] J. Q. Hang, "A new type of controller: NLPID," Controland Decision, vol. 9, pp. 410-407, 1994.

[11] S. H. Li, S. H. Ding, and Y. P. Tian, "A finite-time state feedback stabilization method for a class of second order nonlinear systems," Acta Automatica Sinica, vol. 33, no. 1, p. 0101, 2007.

[12] X. Huang, W. Lin, and B. Yang, "Global finite-time stabilization of a class of uncertain nonlinear systems," Automatica, vol. 41, no. 5, pp. 881-888, 2005.

[13] S. T. Venkataraman and S. Gulati, "Terminal sliding modes: a new approach to nonlinear control synthesis," in Proceedings of the International Conference on, Advanced Robotics, Pisa, Italy, June 1991.

[14] P. Shi, Y. Xia, G. P. Liu, and D. Rees, "On designing of slidingmode control for stochastic jump systems," IEEE Transactions on Automatic Control, vol. 51, no. 1, pp. 97-103, 2006.

[15] Y. Feng, X. Yu, and Z. Man, "Non-singular terminal sliding mode control of rigid manipulators," Automatica, vol. 38, no. 12, pp. 2159-2167, 2002. 
[16] X. Yu and Z. Man, "Fast terminal sliding-mode control design for nonlinear dynamical systems," IEEE Transactions on Circuits and Systems I: Fundamental Theory and Applications, vol. 49, no. 2, pp. 261-264, 2002.

[17] S. Shi, Y. Fang, J. Li, and Z. Jiao, "Adaptive position tracking control for electro-hydraulic servo system with input saturation," ICIC Express Letters, vol. 6, no. 10, pp. 2699-2704, 2012.

[18] G. Bartolini, A. Ferrara, and E. Usai, "Chattering avoidance by second-order sliding mode control," IEEE Transactions on Automatic Control, vol. 43, no. 2, pp. 241-246, 1998.

[19] E. Lu, W. Li, X. Yang, and Y. Liu, "Anti-disturbance speed control of low-speed high-torque PMSM based on secondorder non-singular terminal sliding mode load observer," ISA Transactions, vol. 88, pp. 142-152, 2019.

[20] W. Shen, H. L. Huang, and J. H. Wang, "Robust backstepping sliding mode controller Investigation for a port plate position servo system based on an extended states observer," Asian Journal of Control, vol. 21, no. 1, pp. 302-311, 2019.

[21] J. Han, "From PID to active disturbance rejection control," IEEE Transactions on Industrial Electronics, vol. 56, no. 3, pp. 900-906, 2009.

[22] Z. Gao, "Scaling and bandwidth-parameterization based controller tuning," in Proceedings of the IEEE 2003 American Control Conference, pp. 4989-4996, Denven, CO, USA, June 2003.

[23] Z. Wang, J. Li, J. Wang, F. Zhang, and L. Zhao, "Active disturbance rejection control for electro-hydraulic servo system of aluminum strip cold rolling mill," in Proceedings of the 32nd Chinese Control Conference, Xi' an, China, July 2013.

[24] B. Sun and Z. Gao, "A DSP-based active disturbance rejection control design for a $1 \mathrm{~kW}$ h-bridge DC-DC power converter," IEEE Transactions on Industrial Electronics, vol. 52, no. 5, pp. 1271-1277, 2005.

[25] J. Yao, Z. Jiao, and D. Ma, "Adaptive robust control of DC motors with extended state observer," IEEE Transactions on Industrial Electronics, vol. 61, no. 7, pp. 3630-3637, 2014.

[26] X. Shao and H. Wang, "Active disturbance rejection based trajectory linearization control for hypersonic reentry vehicle with bounded uncertainties," ISA Transactions, vol. 54, pp. 27-38, 2015.

[27] H. Sira-Ramirez, J. Linares-Flores, C. Garcia-Rodriguez, and M. A. Contreras-Ordaz, "On the control of the permanent magnet synchronous motor: an active disturbance rejection control approach," IEEE Transactions on Control Systems Technology, vol. 22, no. 5, pp. 2056-2063, 2014.

[28] D. C. Tang, Z. Q. Gao, and X. H. Zhang, "Design of predictive active disturbance rejection controller for turbidity," Control Theory and Applications, vol. 34, no. 1, pp. 101-108, 2017.

[29] Y. Xia, P. Shi, G. P. Liu, D. Rees, and J. Han, "Active disturbance rejection control for uncertain multivariable systems with time-delay," IET Control Theory and Applications, vol. 1, no. 1, pp. 75-81, 2007.

[30] Z.-H. Liu, Y.-J. Zhang, Z. Jing, and J.-H. Wu, "Active disturbance rejection control of a chaotic system based on immune binary-state particle swarm optimization algorithm," Acta Physica Sinica, vol. 60, no. 1, pp. 791-799, 2011.

[31] J. Yao and W. Deng, "Active disturbance rejection adaptive control of hydraulic servo systems," IEEE Transactions on Industrial Electronics, vol. 64, no. 10, pp. 8023-8032, 2017.

[32] C. Wang, L. Quan, S. Zhang, H. Meng, and Y. Lan, "Reducedorder model based active disturbance rejection control of hydraulic servo system with singular value perturbation theory," ISA Transactions, vol. 67, pp. 455-465, 2017.
[33] B. Gao, J. Shao, and X. Yang, "A compound control strategy combining velocity compensation with ADRC of electrohydraulic position servo control system," ISA Transactions, vol. 53, no. 6, pp. 1910-1918, 2014.

[34] Y. M. Fang, Z. J. Wang, Y. P. Xie et al., "Sliding mode variable structure control of multi-model switching for rolling mill hydraulic servo position system," Electric Machines \& Control, vol. 5, pp. 91-96, 2010.

[35] J. Han and L. Yuan, "The discrete form of tracking-differentiator," System Science and Mathematics, vol. 19, no. 3, pp. 268-273, 1999.

[36] W. Zhang and J. Han, "Tracking differentiator for continuous system identification," Control and Decision, vol. 14, pp. 557-560, 1999.

[37] Z.-L. Han and B.-Z. Guo, "A nonlinear extended state observer based on fractional power functions," Automatica, vol. 81, pp. 286-296, 2017.

[38] Y. Feng, X. Yu, and F. Han, "On nonsingular terminal slidingmode control of nonlinear systems," Automatica, vol. 49, no. 6, pp. 1715-1722, 2013. 